\title{
Right Ventricular Myxoma Causing Right Ventricular Outflow Tract Obstruction: A Case Report
}

\author{
Xuemei Jiang1, Yang Wang1, Werner Mohl2, Zhongyi Si $^{3 *}$ \\ ${ }^{1}$ Department of Cardiac Surgery, The First Hospital of Liaoning Medical University, Jinzhou, China \\ ${ }^{2}$ Department of Cardiac Surgery, AKH, Medical University of Vienna, Vienna, Austria \\ ${ }^{3}$ Department of Cardiac and Vascular Surgery, Panjin Central Hospital, Panjin, China \\ Email: ${ }^{*}$ zhongyi85@hotmail.com
}

Received 22 July 2015; accepted 22 September 2015; published 25 September 2015

Copyright (C 2015 by authors and Scientific Research Publishing Inc.

This work is licensed under the Creative Commons Attribution International License (CC BY).

http://creativecommons.org/licenses/by/4.0/

(c) (i) Open Access

\begin{abstract}
A 63-year-old patient presented with dyspnea and chest distress. A computerized tomography and echocardiogram showed a cardiac mass in the right ventricle, which caused obstruction of the right ventricular outflow tract. Coronary angiography revealed a dense meshwork of the abnomorly capillary vessels originating from right coronary artery. The mass was completely excised under cardiopulmonary bypass. The mass attached right ventricle lateral wall and posterior triscupid leaflet. Histology was typical myomatous tissue.
\end{abstract}

\section{Keywords}

Myxoma, Cardiac Tumor, Right Ventricular Outflow Tract

\section{Background}

Cardiac myxomas are mostly benign tumor, and rarely originate from right ventricule [1]. The clinical symptoms are depended on the size and location of the tumors, which always cause the serious complications, arrhythmias, pulmonary embolism, syncope and sudden death. We report a case of primary right ventricular myxoma causing right ventricular outflow tract obstruction.

\section{Case Report}

A 63-year old female presented with 10 years history of increasing shortness of breath and chest distress with "Corresponding author.

How to cite this paper: Jiang, X.M., Wang, Y., Mohl, W. and Si, Z.Y. (2015) Right Ventricular Myxoma Causing Right Ventricular Outflow Tract Obstruction: A Case Report. Open Journal of Clinical Diagnostics, 5, 121-124.

http://dx.doi.org/10.4236/ojcd.2015.53020 
aggreavating symptoms in the last month. When she came in the out-patient clinic, physical findings showed that her heart rate was 70/min, rhythm was regular, and blood pressure of 112/85 mmHg. A grade 2/6 systolic ejection murmur was heard at the left upper sternal border. ECG was normal. The size of the mass confirmed by Echocardiography was $70 \times 40 \times 20 \mathrm{~mm}$, which was attached to the right ventricle lateral wall, near to the root of tricuspid valve (Figure 1). Enhanced computerized tomography scan of the chest revealed a large filling defect which measured $35.5 \times 38.7 \mathrm{~mm}$ in the right ventricle extending into the pulmonary trunk (Figure 2). Coronary angiography showed that left main coronary, left anterior descending, circumflex coronary and right coronary were normal, right marginal branch of right coronary sent out nutrient vessel (Figure 3).

An operation was done in November 2012, under general anaesthesia and extracorporeal circulation. The pericardal effusion was founded mediumly, the right ventricle and the right atrium was markedly dilated and hypertrophied. After making an incision in the right atrium, a large tumor mass was seen along the right ventricular outflow tract, attached to the posterior tricuspid valve and right ventricular posterior wall, extending into the right ventricular outflow tract. The tumour was fixed so that the total dimension especially the part in the outflowtract was difficult to assess. For better visibility we performed another incision on the main pulmonary artery. Again only part of the tumour was seen in the right ventricular outflowtract, so that the incision had to be extended into the right ventricular inflow tract. Now the tumor measuring $30 \times 50 \mathrm{~mm}$, and of mucous, gelatinous appearance, with a stem fixed to the subvalvular region could be excised easily (Figure 4). The part of posterior leaflet and the tricuspid valve was repaired without annuloplasty ring. Tricuspid valve function was checked by filling the right ventricule with saline, the valve leaflet closed well. The postoperative pathological diagnosis was myxoma. Microscopic findings showed typical myxomatous tissue with high cellularity, however no malignancy was observed (Figure 5). Postoperative echocardiography revealed right ventricule function normally and tricuspid valvualr function without regurgitation. Follow-up was one year and echocardiography revealed no evidence of tricuspid valve regurgitation and no sign of local recurrence of myxoma.

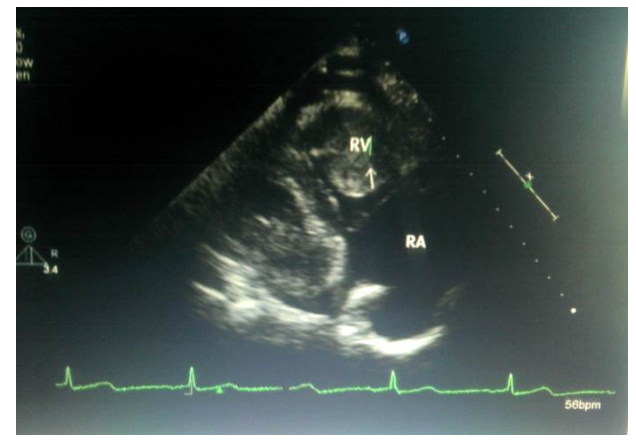

Figure 1. Echocardiography revealed right ventricular space-occupying lesions (arrow).

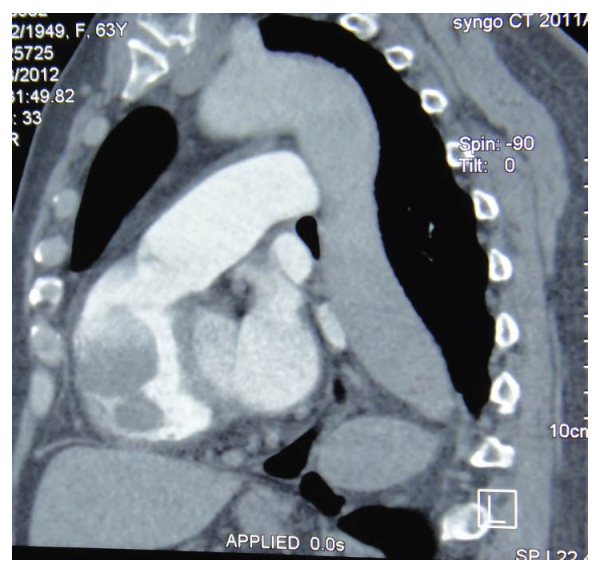

Figure 2. Enhanced computerized tomography scan of the chest revealed a large filling defect in the right ventricluar outflow tract (arrow). 


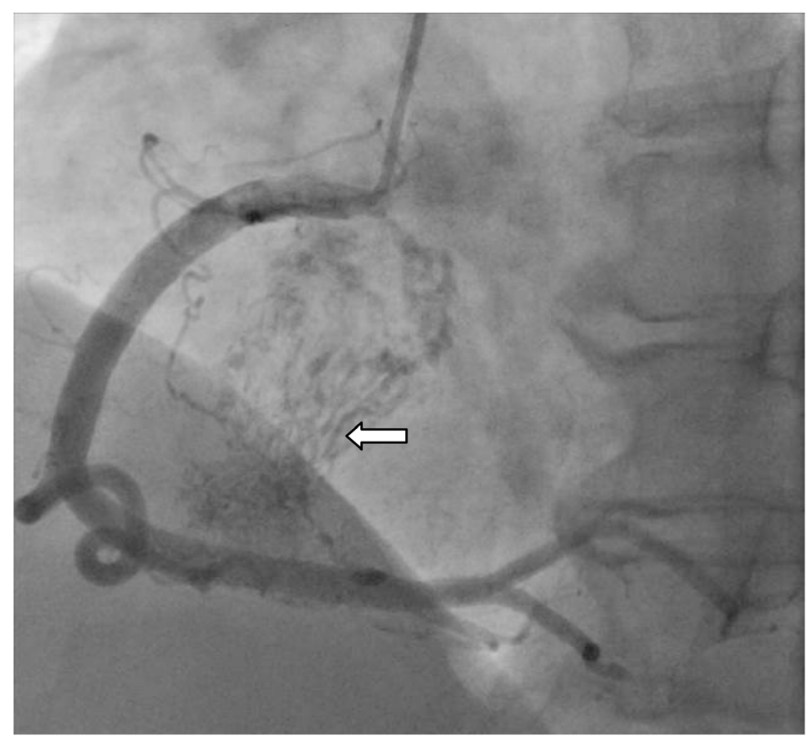

Figure 3. Coronary angiography showed that right coronary were normal, right marginal branch of right coronary sent out nutrient vessel (arrow).

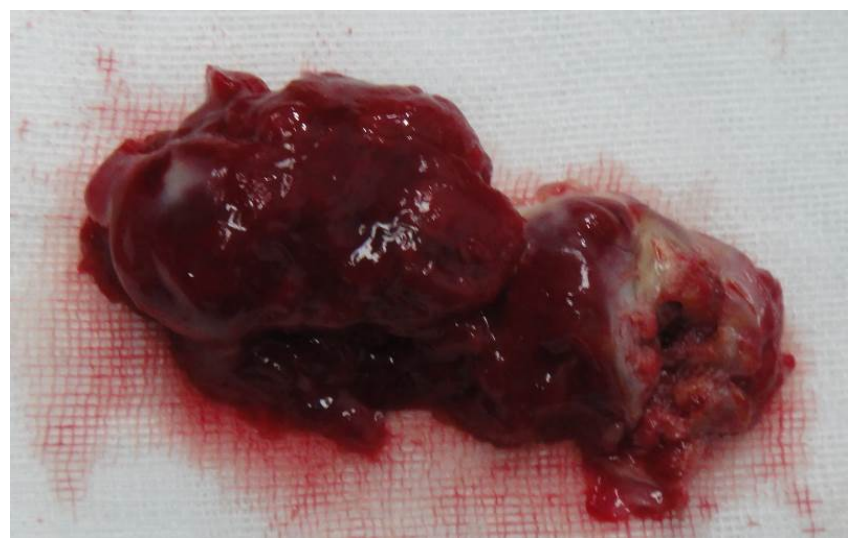

Figure 4. The resected specimen.

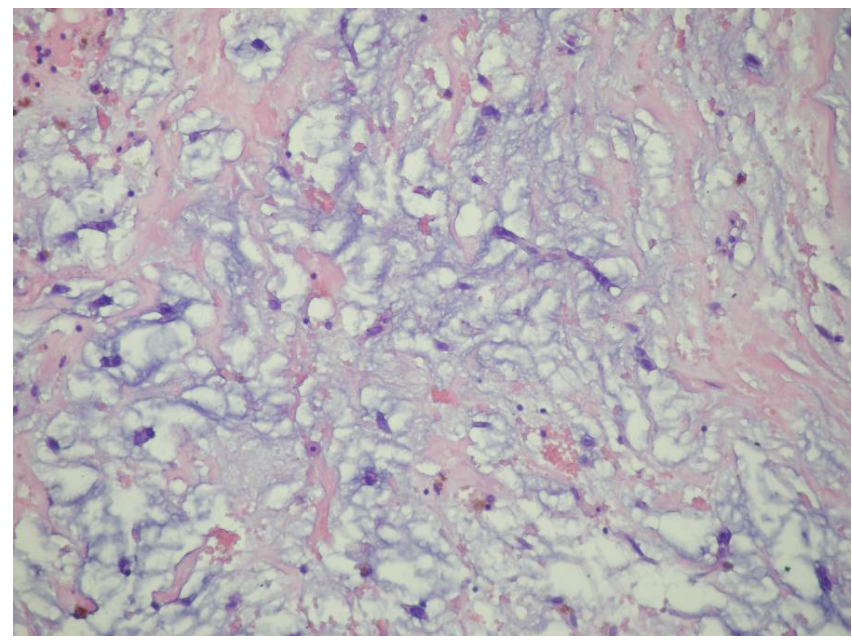

Figure 5. Histology of tumor typical of a myxoma. 


\section{Discussion}

The majority of cardiac tumors are benign myxomas. Atrial myxoma most commonly arises from the left atrium, and less frequently from the right atrium or both ventricles [2] [3]. Patients may be asymptomatic in early, with the growth of tumor, the clinical symptoms appear. Clinical manifestation includes fever, chest distress, dyspnea, anaemia, syncopal attack, embolism and so on. The patient of present report case developed dyspnea, and physical inactivity, presented right heart failure as a result of right ventricular outflow tract obstruction. Computertomography confirmed distal pulmonar artery embolization and tumour location in the heart chamber. The surgical operation treatment was the first choice. The surgical approach may be via right atrium, pulmonary artery, or right ventricule. Since the tumour in this case was giant, and attached to the posterior tricuspid valve and right ventricular posterior wall, it could not been seen by extending the incision up to the main stem of the pulmonary artery and with a short helping incision in the right outflow tract thus perserving as much of right ventricular myocardium and sparing out the pulmonary valve. The tumor was adherent to the posterior tricuspid valve, tendineae chordae and right ventricular posterior wall, tumors pedicle attached to the endocardium of the right ventricular posterior wall and the tumor was immobile. The relating tissues adhering to the tumor tightly, tendineae chordae, part of posterior valve leaflet were excised completely. Thus tricuspid valve leaflet was repaired to prevent tricuspid regurgitation.

If the tumor excised completely including to the adjacent tissues, to prevent to myxoma reoccur, annuloplasty was considered in the most appropriate treatment option [4] [5].

\section{References}

[1] Hirota, J., Akiyama, K., Taniyasu, N., Maisawa, K., Kobayashi, Y., Sakamoto, N. and Komatsu, N. (2004) Injury to the Tricuspid Valve and Membranous Atrioventricular Septum Caused by Huge Calcified Right Ventricular Myxoma: Report of a Case. Circulation Journal, 68, 799-801. http://dx.doi.org/10.1253/circj.68.799

[2] Gopal, A.S., Arora, N.S. and Messineo, F.C. (2000) Right Ventricular Myxoma. New England Journal of Medicine, 342, 295. http://dx.doi.org/10.1056/NEJM200001273420418

[3] Sá, M.I., Abreu, A., Cabral, S., Torres, S., de Oliveira, F., Antunes, M., et al. (2007) Myxoma in the Right Ventricular Outflow Tract. Revista Portuguesa de Cardiologia, 26, 377-381.

[4] Tsang, F.H. and Cheng, L.C. (2011) Giant Myxoma Causing Right Ventricular Outflow Tract Obstruction. Hong Kong Medical Journal, 17, 242-244.

[5] Cho, S.H., Shim, M.-S., Kim, W.S. (2015) The Right Ventricular Myxoma Which Attached to the Tricuspid Valve: Sliding Tricuspid Valvuloplasty. Korean Journal of Thoracic and Cardiovascular Surgery, 48, 228-230. http://dx.doi.org/10.5090/kjtcs.2015.48.3.228 